\title{
Rad51-dependent DNA structures accumulate at damaged replication forks in sgs 1 mutants defective in the yeast ortholog of BLM RecQ helicase
}

\author{
Giordano Liberi, ${ }^{1,3,5}$ Giulio Maffioletti, ${ }^{1,3}$ Chiara Lucca, ${ }^{1}$ Irene Chiolo, ${ }^{1}$ Anastasia Baryshnikova, ${ }^{1}$ \\ Cecilia Cotta-Ramusino, ${ }^{1}$ Massimo Lopes, ${ }^{1,4}$ Achille Pellicioli, ${ }^{1}$ James E. Haber, ${ }^{2}$ and Marco Foiani ${ }^{1}$ \\ ${ }^{1}$ F.I.R.C. Institute of Molecular Oncology Foundation, 20141, Milan, Italy and Dipartimento di Scienze Biomolecolari e \\ Biotecnologie, University of Milan, Milan, Italy; ${ }^{2}$ Rosenstiel Center and Department of Biology, Brandeis University, \\ Waltham, Massachusetts, USA
}

\begin{abstract}
S-phase cells overcome chromosome lesions through replication-coupled recombination processes that seem to be assisted by recombination-dependent DNA structures and/or replication-related sister chromatid junctions. RecQ helicases, including yeast Sgs1 and human BLM, have been implicated in both replication and recombination and protect genome integrity by preventing unscheduled mitotic recombination events. We have studied the RecQ helicase-mediated mechanisms controlling genome stability by analyzing replication forks encountering a damaged template in sgs1 cells. We show that, in sgs1 mutants, recombination-dependent cruciform structures accumulate at damaged forks. Their accumulation requires Rad51 protein, is counteracted by Srs2 DNA helicase, and does not prevent fork movement. Sgs1, but not Srs2, promotes resolution of these recombination intermediates. A functional Rad53 checkpoint kinase that is known to protect the integrity of the sister chromatid junctions is required for the accumulation of recombination intermediates in sgs 1 mutants. Finally, top3 and top3 sgs 1 mutants accumulate the same structures as sgs1 cells. We suggest that, in sgs1 cells, the unscheduled accumulation of Rad51-dependent cruciform structures at damaged forks result from defective maturation of recombination-dependent intermediates that originate from the replication-related sister chromatid junctions. Our findings might contribute to explaining some of the recombination defects of BLM cells.
\end{abstract}

[Keywords: Sgs1; RecQ helicases; DNA replication; recombination; checkpoint; Srs2]

Supplemental material is available at http://www.genesdev.org.

Received August 21, 2004; revised version accepted December 3, 2004.

Homologous recombination is required to repair chromosomal lesions, to assist DNA synthesis, to provide genetic variation, or even to regulate gene expression (Pâques and Haber 1999; Cox 2001; West 2003). In particular, cells experiencing DNA damage while replicating the chromosomes need to couple recombination to replication to overcome the DNA lesions on the template (Kogoma 1997; Pâques and Haber 1999; Foiani et al. 2000; Rhind and Russell 2000). Break-induced replication (BIR) (Signon et al. 2001; Davis and Symington 2004)

\footnotetext{
${ }^{3}$ These authors contributed equally to this work. Present address: ${ }^{4}$ Institute of Cell Biology, ETH Hönggerberg, CH-8093 Zürich, Switzerland.

${ }^{5}$ Corresponding author.

E-MAIL giordano.liberi@ifom-ieo-campus.it; FAX 39-02-574303231. Article and publication are at http://www.genesdev.org/cgi/doi/10.1101/ gad.322605.
}

and template switching (Higgins et al. 1976) may represent possible options for the cell to counteract the dangerous consequences of intra-S DNA damage. Although the genetic requirements of BIR have been defined, the mechanisms and the factors required to promote template switching are still unknown.

However, recombination can also be a source of DNA damage as unscheduled recombination events may contribute to genome instability and tumorigenesis (FloresRozas and Kolodner 2000). This is the case in the Bloom and Werner cancer-prone syndromes, resulting from mutations in the BLM and WRN genes, respectively, that exhibit enhanced genome instability due to hyperactivation of certain recombination processes. These genes have been implicated in homologous recombination and belong to the highly conserved RecQ DNA helicase gene family (Shen and Loeb 2001; Hickson 2003; Khakhar et al. 2003). 
In vitro studies have demonstrated that the RecQ DNA helicases are able to separate the complementary DNA strands with 3'-to-5' polarity in a ATP-dependent manner, but also disrupt a variety of DNA structures, including Holliday junctions (HJs), through a branch migration-like activity (Shen and Loeb 2001; Hickson 2003; Khakhar et al. 2003). HJs are cruciform structures that represent key intermediates in DNA recombination. HJs and HJ-like intermediates have been suggested to arise also during DNA replication, most notably at the rDNA locus (Zou and Rothstein 1997), in the presence of a damaged template (Kowalczykowski 2000), as a result of fork regression (Inmann 1984; Michel et al. 2001; Sogo et al. 2002), or when BIR is occurring (Pâques and Haber 1999). Some of these events seem to represent pathological situations rather than physiological options as in the case of reversed forks that accumulate in response to replication blocks in the absence of a functional checkpoint but not in wild-type cells (Lopes et al. 2001; Sogo et al. 2002). HJ formation can be promoted by the presence of gaps/nicks on DNA and double-strand breaks (DBS) (Heyer et al. 2003) or even from the processing of hemicatenane structures (Schwacha and Kleckner 1995; Lopes et al. 2003).

It has been recently shown that four-way sister chromatid junctions (SCJs), resembling hemicatenanes, form at origins of replication during $S$ phase (Lopes et al. 2003). These structures are able to branch migrate behind moving replication forks and have been suggested to assist sister chromatid-mediated recombination and replication bypass processes and, in particular, template switching (Lopes et al. 2003). Although SCJ formation is not influenced by DNA damage and does not depend on homologous recombination proteins, these structures can be converted into HJ-like molecules: This is the case in checkpoint mutants where SCJs seem to contribute to the formation of reversed forks (Lopes et al. 2003) due to a defective replisome-fork association (Lucca et al. 2004). Further, the SCJ/hemicatenane structure could, in theory, result in double HJs or pseudo double HJs (Schwacha and Kleckner 1995; Lopes et al. 2003), while the opposite transition can be promoted by collapsing together two HJs, thus leading to the formation of hemicatenanes (Carr 2002; Heyer et al. 2003; Ira et al. 2003).

Mutations in the Saccharomyces cerevisiae SGS1 gene, encoding the only RecQ homolog, cause gross chromosomal rearrangements (Myung et al. 2001) and confer a hyper-recombination phenotype (Gangloff et al. 1994; Watt et al. 1996). The absence of Sgs1 also causes an increase in both mitotic (Ira et al. 2003) and meiotic (Rockmill et al. 2003) recombination. Interestingly, a dramatic stimulation of both sister chromatid exchanges (SCE) and interchromosomal recombination has been observed in human cells carrying genetic defects in the Bloom's syndrome gene (German 1993; Hickson 2003).

Altogether, these observations have contributed to the hypothesis that RecQ helicases may be required to prevent unscheduled recombinogenic events (Hickson 2003). However, it should be pointed out that the recombination phenotype of RecQ defective cells seem to be more complex: In fact, the WRN protein is needed to generate viable mitotic recombinants in unperturbed conditions (Prince et al. 2001) and sgs1 mutants are defective in DNA damage-induced heteroallelic recombination (Gangloff et al. 2000; Onoda et al. 2001), suggesting a positive role for RecQ DNA helicases in promoting recombination in certain contexts. Accordingly, genetic evidence and in vitro studies have implicated RecQ helicases not only in preventing the accumulation of recombination intermediates but also in promoting their resolution (Harmon and Kowalczykowski 1998; Fabre et al. 2002; Ira et al. 2003).

In particular, a role for Sgs 1 in contributing to the maturation of recombination structures is in agreement with the findings that the detrimental effect of homologous recombination in top3 mutants depends on a functional SGS1 gene (Gangloff et al. 1999; Shor et al. 2002) and that Sgs1 physically interacts with the recombination protein Rad51 (Wu et al. 2002). Further, genetic and physical interactions between the type I topoisomerase Top3 and Sgs1 have been described (Gangloff et al. 1994; Bennet et al. 2000; Fricke et al. 2001). RecQ helicases, in combination with Top3, have been suggested to play a role in resolving double $\mathrm{HJs}$ through formation of hemicatenanes (Carr 2002; Heyer et al. 2003). Recent observations have indeed established that both Top3 and Sgs1 are required to prevent mitotic crossovers by processing and resolving double $\mathrm{HJ}$ s generated in response to DSB formation (Ira et al. 2003). Similar conclusions have been obtained by in vitro studies using Blm and TopIII $\alpha$ proteins, demonstrating that this complex dissolves double $\mathrm{HJs}$ avoiding crossovers outcome $(\mathrm{Wu}$ and Hickson 2003).

Sgs1 is functionally related to Srs2, another $3^{\prime}$-to-5' DNA helicase (Rong and Klein 1993) that is phosphorylated in response to DNA damage though a mechanism dependent on Cdk1 and on a functional checkpoint (Liberi et al. 2000). SRS2 and SGS1 seem to have both unique and partially overlapping functions. Extensive genetic data have shown that inactivation of both Sgs1 and Srs2 causes a near lethal phenotype that can be rescued by inhibiting homologous recombination, thus suggesting that Sgs1 and Srs2 counteract toxic recombination events (Gangloff et al. 2000; Klein 2001; McVey et al. 2001), possibly through distinct mechanisms (Fabre et al. 2002). It has been suggested that these lethal events may arise spontaneously during DNA replication, rather than in response to DSB formation (Fabre et al. 2002). Moreover, deletions of either gene show a number of synthetic lethal genetic interactions with other replication-associated mutations (Ooi et al. 2003). Both Srs2 and Sgs1 have been implicated in the intra-S DNA damage checkpoint response (Frei and Gasser 2000; Liberi et al. 2000). Further, Srs2 is specifically required for recovery and adaptation in response to checkpoint-mediated arrest prior to repair of a DSB (Vaze et al. 2002), whereas Sgs1 is also implicated in telomere maintenance (Huang et al. 2001).

Interestingly, srs2 mutants exhibit a complex recombination phenotype, since they are prorecombinogenic in some contexts (Pâques and Haber 1997; Hegde and Klein 
2000; Ira and Haber 2002; Aylon et al. 2003) but antirecombinogenic in others (Aboussekhra et al. 1989; Rong et al. 1991). In addition, recent in vitro experiments have unmasked a Srs2 translocase activity required to disrupt Rad51 nucleofilament, an early intermediate in $\mathrm{HJ}$ formation (Krejci et al. 2003; Veaute et al. 2003).

Here we show that sgs 1 mutants accumulate cruciform DNA molecules at damaged replication forks without impairing fork progression. The formation of these branched structures requires functional Rad51 and Rad52 proteins and is prevented by Srs 2 helicase. We also show that subsequent expression of Sgs1, but not Srs2, is able to promote the resolution of the recombination intermediates at damaged forks. We suggest that Sgs1 and, more generally RecQ helicases, together with Top3 topoisomerase act at damaged replication forks to resolve recombination structures likely resulting from replication-related SCIs. Accordingly, we show that the accumulation of the X-shaped Rad51-dependent intermediates in sgs1 mutants requires a functional Rad53 checkpoint kinase that controls the integrity of the SCJs.

\section{Results}

We have studied the role of Sgs1 in controlling chromosome integrity during unperturbed DNA replication and in response to methyl methane sulfonate (MMS)-induced intra-S DNA damage that causes chromosomal rearrangements in wild-type and, to a greater extent, in sgs1 cells (Myung and Kolodner 2002). Using the neutral-neutral two-dimensional (2D) gel electrophoresis technique (Brewer and Fangman 1987), we have analyzed the quality, progression, and processing of replication forks originating from ARS305 (Fig. 1A; Newlon et al. 1993). In wild type and $s g s 1 \Delta(s g s 1)$ cells released from G1 under unperturbed conditions, ARS305 has already fired at 20 min, as shown by the appearance of bubbles and large Y-shaped molecules (resulting from asymmetric progression of forks out of the ARS305 restriction fragment) (Fig. 1B). We note that origin firing occurs slightly earlier in sgs1 than in wild-type cells (Supplementary Fig. S1); we observed this phenomenon also in other replication/ recombination mutants (Lopes et al. 2003; data not shown) that, like sgs1 are large sized (Sinclair et al. 1998) and, therefore, at the time of cell division, spend less time in G1 than wild-type cells to reach the critical mass required for entry into S phase (Murray and Hunt 1993). $\mathrm{X}$-shaped molecules are also detected in both wild-type and sgs 1 cells. We will refer to these X-shaped molecules as SCJs.

We conclude that, under normal conditions, the quality of replication intermediates is comparable in the two strains, although the kinetics of origin firing is slightly anticipated in sgs 1 cells.

Wild-type and sgs 1 cells were then released from G1 in the presence of MMS (Paulovich and Hartwell 1995). In wild-type cells, bubbles accumulate at ARS305 by 20-60 min, while the maximum accumulation of SCJs occurs at $90 \mathrm{~min}$ (Fig. 2A). We then analyzed the forks that, from $A R S 305$, invade chromosomal regions $\mathrm{A}$ and $\mathrm{B}$ po-

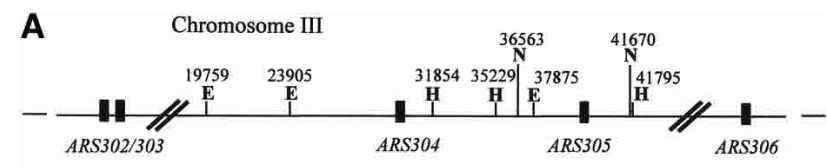

B
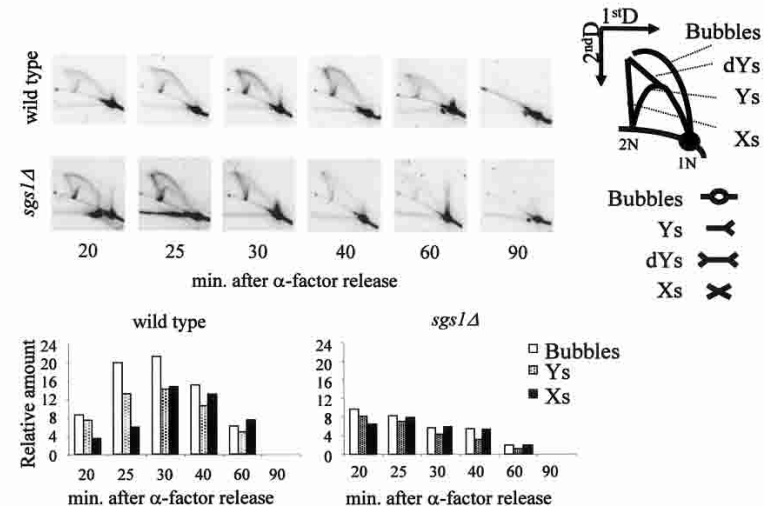

Figure 1. Wild-type and $s g s 1$ cells exhibit the same pattern of replication intermediates under unperturbed conditions. (A) Genomic region containing ARS305 origin (Newlon et al. 1993); restriction sites are indicated as follows: $\mathrm{NcoI}(\mathrm{N}), \operatorname{EcoRV}(\mathrm{E})$, HindIII (H). (B) W303-1A (wild-type) and CY2570 (sgs1D) strains were presynchronised in G1 by $\alpha$-factor treatment and released into fresh medium at $23^{\circ} \mathrm{C}$ under unperturbed conditions. DNA was prepared from cells collected at the indicated times, cut with NcoI, and analyzed by 2D gel using the ARS305 probe. Quantification analysis of replication intermediates is also presented.

sitioned 4.3 and 15.7 kilobases $(\mathrm{kb})$, respectively, to the left of ARS305. Some forks have already invaded region $\mathrm{A}$ by $20 \mathrm{~min}$ as judged by the presence of the $\mathrm{Y}$ arc (Fig. 2A). No SCJs were detected at $20 \mathrm{~min}$. The relative level of the $\mathrm{Y}$ arc in region A peaks at 40 min, suggesting that most of the forks replicate region $\mathrm{A}$ at that time. At $40 \mathrm{~min}$ the SCJs become visible, peaking at $90 \mathrm{~min}$. At later time points, the $\mathrm{Y}$ arc and the SCJs disappear from region $A$ as the forks continue to move away from ARS305. The first forks invade region B at 40 min but, again, the SCJs only begin to accumulate 20 min later. These data support previous observations indicating that forks move slowly in the presence of MMS (Tercero and Diffley 2001; Lopes et al. 2003), and that SCJs form at the origins and branch migrate, chasing the forks, although their appearance is delayed compared to the onset of the Y molecules (Lopes et al. 2003). We note that the accumulation of the SCJ structures in wild-type and sgs1 cells grown under normal conditions and in MMS-treated wild-type cells does not depend on the homologous recombination proteins Rad52 and Rad51 (see below; Lopes et al. 2003).

In MMS-treated sgs1 cells, the kinetics of appearance/ disappearance of bubbles and $\mathrm{Y}$ molecules at ARS305 and at regions $\mathrm{A}$ and $\mathrm{B}$ are similar to those shown in wild-type cells (Fig. 2A,B), and the same is true for the bulk of DNA synthesis, as judged by FACS analysis (Fig. 2C). However, the accumulation of $\mathrm{X}$ molecules is remarkably different: While the appearance of the $\mathrm{X}$ 
A

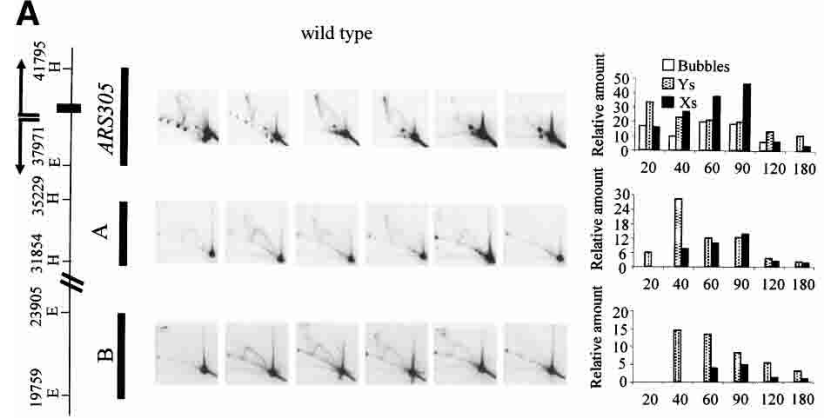

B
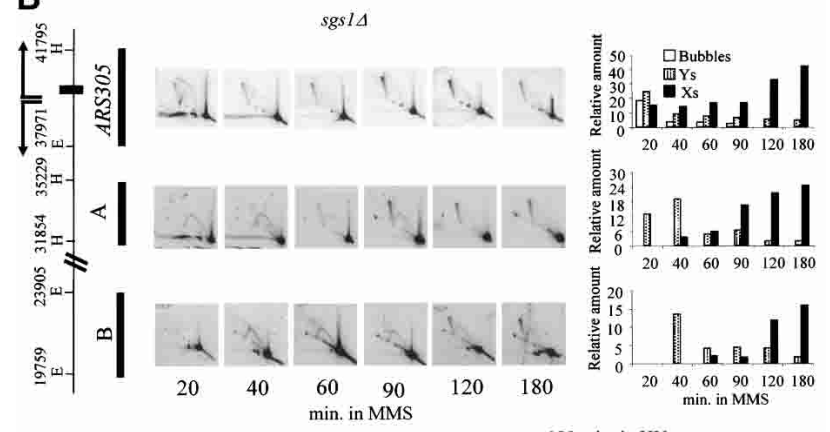

C
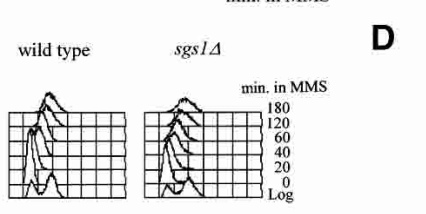

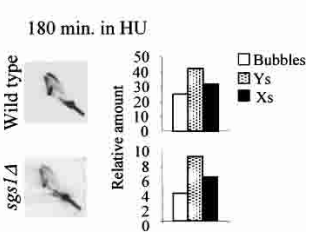

Figure 2. X-shaped molecules accumulate at replication forks in $s g s 1$ mutants following exposure to MMS but not HU. Wildtype $(A)$ and $\operatorname{sgs} 1 \Delta(B)$ strains were presynchronised in G1 by $\alpha$-factor treatment and released into fresh medium containing MMS. DNA samples were taken at the indicated times, cut with HindIII and EcoRV, and analyzed by $2 \mathrm{D}$ gel. The membranes were subsequently hybridized with probes against $A R S 305$, region $\mathrm{A}$, and region $\mathrm{B}$. (C) FACS analysis was performed on cells collected at the indicated times. $(D)$ Wild-type and $s g s 1 \Delta$ strains were presynchronised by $\alpha$-factor treatment in $\mathrm{G} 1$ and released at $25^{\circ} \mathrm{C}$ into fresh medium in the presence of HU. DNA samples were analyzed using the ARS305 probe as in $A$ and $B$.

structures at $A R S 305$ and regions $\mathrm{A}$ and $\mathrm{B}$ seems to occur with the same kinetics as in wild-type cells, their relative intensity increases with time rather than diminishing. In fact, at 120-180 min, the relative amount of the $\mathrm{X}$ molecules is higher than at $20-40 \mathrm{~min}$ and very similar in ARS305, A, and $\mathrm{B}$ regions, suggesting that a fraction of $\mathrm{X}$ structures keeps accumulating in sgs1 cells. We conclude that, in our experimental conditions, fork progression is similar in MMS-treated wild-type and sgs1 cells. However, sgs1 mutants exhibit an abnormal accumulation of X-shaped structures that specifically depend upon the presence of a damaged template. This phenomenon is not due to an initiation defect but rather is related to a post-replicative problem since it occurs after origin firing and after the passage of the fork. Further, the accumulation of X-shaped structures is not seen when replication is stalled by hydroxyurea (HU) (Fig. 2D). The abnormal accumulation of $\mathrm{X}$ molecules observed in MMS-treated sgs1 cells, together with the observation that a population of $\mathrm{X}$ structure is indeed able to migrate with the same kinetics as in MMS-treated wild-type cells, raises the question as to whether the $\mathrm{X}$ structures that keep accumulating at late time points represent SCJs or, rather, different intermediates. It should be noted that at least two types of molecules migrate like an X spike on 2D gels: hemicatenanes and HJs (Collins and Newlon 1994; Lockshon et al. 1995; Schwacha and Kleckner 1995; Zou and Rothstein 1997; Lucas and Hyrien 2000; Lopes et al. 2003; Wellinger et al. 2003). Given that SCJs have been suggested to represent hemicatenanes (Lopes et al. 2003), we tested whether the X molecules abnormally accumulating in MMS-treated sgs1 cells were instead recombination-dependent structures. Hence, we tested whether their accumulation was dependent on Rad51/Rad52-mediated recombination events and/or rescued by overexpression of Srs2 that has been implicated in disrupting Rad51 nucleofilaments (Krejci et al. 2003; Veaute et al. 2003). Recent results also suggest that overexpressing $S R S 2$ reduces the proportion of DNA repair events that proceed through a crossoverproducing recombination pathway that likely involves the formation of double HJs (Ira et al. 2003). We found that the damage-induced accumulation of $\mathrm{X}$ intermediates in sgs 1 cells can be prevented by deleting RAD51 or RAD52 (Fig. 3A; data not shown) or by overexpressing $S R S 2$ from a galactose-inducible multicopy plasmid (Fig. 3B). Conversely, overexpression of a helicase/translocase-dead Srs2 mutant protein (Krejci et al. 2004), which accumulates at the same level as wild-type protein, does not influence the level of X molecules in sgs1 mutants (data not shown). However, we note that a population of Rad51/Rad52-independent X molecules, likely representing the SCJs described in untreated wild-type cells, is also found in MMS-treated wild-type, sgs1, rad51, sgs1 rad51, and SRS2-overexpressing cells (Fig. 3).

We conclude that homologous recombination contributes to the accumulation of certain $\mathrm{X}$ molecules in MMS-treated sgs1 cells that, at least from the genetic point of view, differ from the intermediates represented by SCJs, although both these X-shaped structures migrate on 2D gels similarly. We will refer to the recombination-dependent X-molecules as rec-Xs.

We then tested whether the Srs2 and Sgs1 helicases are able to promote the resolution of the rec-Xs in sgs1 mutants. We treated $s g s 1$ cells for $3 \mathrm{~h}$ with MMS to promote the accumulation of rec-Xs and we then overexpressed either Srs2 or Sgs1 helicases using a galactose-inducible promoter. Sgs1, but not Srs2, overexpression causes a reduction in the level of the rec-Xs that, with time, become barely detectable (Fig. 4). We note that Srs2 and Sgs1 were properly overexpressed (data not shown). Hence, we conclude that Sgs1 is able to mediate the resolution of the recombination-dependent structures, whereas Srs2 is unable to resolve them.

The previous results suggest that SCJs and rec-Xs are somehow different, although, in principle, SCJs could be converted into rec-X molecules, perhaps due to an active 
A

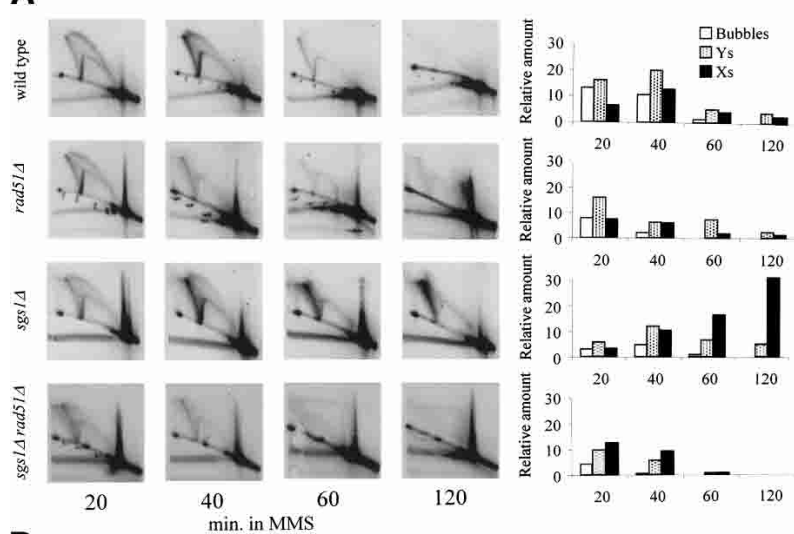

B

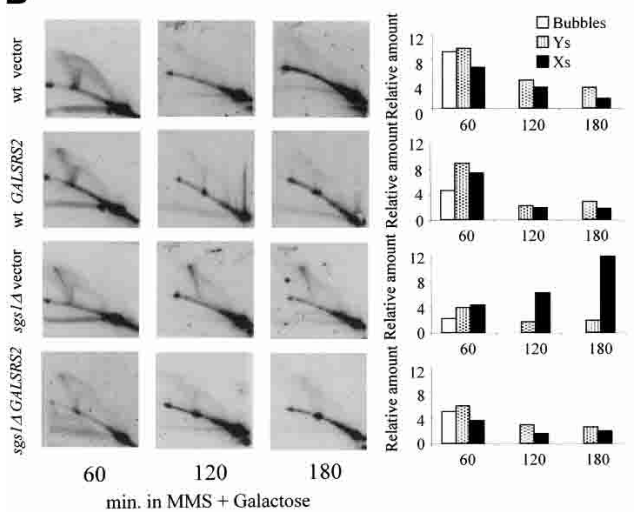

Figure 3. Accumulation of X-shaped intermediates in MMStreated sgs 1 cells requires Rad51 and is rescued by $S R S 2$ over-

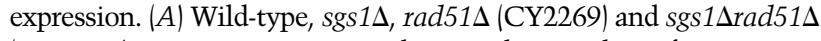
(CY5410) strains were presynchronised in G1 by $\alpha$-factor treatment and released into fresh medium containing MMS. (B) W303-1A [pYES2] (wild-type vector), W303-1A [pAN8] (wildtype GAL-SRS2), CY2570 [pYES2] (sgs1D vector), and CY2570 [pAN8] (sgs1 $G A L$-SRS2) strains were grown in selective medium containing raffinose, synchronized in G1, and released into fresh medium containing MMS and galactose to induce $S R S 2$ overexpression. DNA samples were processed by $2 \mathrm{D}$ gel analysis as in Figure 1B.

process mediated by recombination factors. To try to address this issue we took advantage of rad53 mutants in which the SCJs form normally at the origins of replication but progressively degenerate at collapsed replication forks into other intermediates (Lopes et al. 2003). Consequently, a large fraction of the SCJs, with time, are converted into gapped molecules (that cannot be longer visualized as $\mathrm{X}$ molecules on $2 \mathrm{D}$ gels as they cannot be cut with a restriction enzyme), while a smaller fraction contributes to the formation of a cone signal migrating more diffusely on top of the $\mathrm{X}$ spike and representing reversed forks (Lopes et al. 2003; see also Fig. 5A). If the SCJs somehow influence the formation of the rec-Xs in MMS treated sgs1 mutants, then a logical expectation would be that rad53 sgs1 double mutants experiencing MMS treatment would exhibit a reduced amount of recXs. Indeed, we found that MMS-treated sgs1 rad53 mutants exhibit a $2 \mathrm{D}$ profile more similar to rad53 than sgs1 cells as the rec-Xs no longer accumulate (Fig. 5A).
To ask whether the DNA damage checkpoint was required to maintain rec-X structures, we added caffeine to turn off the checkpoint (Vaze et al. 2002) after the formation of the rec-Xs. Despite the complete inactivation of Rad53 kinase observed already at 30 min after caffeine addition (Fig. 5B), the relative level of the rec-Xs remains unaltered for at least $3 \mathrm{~h}$ (Fig. 5B; data not shown).

This result implies that Rad53 inactivation does not influence the stability of the rec-Xs molecules, thus ruling out the possibility that the disappearance of the recXs structures in sgs1 rad53 mutants is due to their unscheduled resolution or destabilization. Altogether, the results shown in Figure 5 indicate that a functional Rad53 contributes to the formation, but not the resolution, of the rec-Xs molecules in MMS-treated sgs1 cells and suggest that SCJs contribute to the formation of rec-Xs.

We note that while the purification of the SCJ intermediates and their visualization is greatly limited by their intrinsic instability (Lopes et al. 2003), the X molecules accumulating in a Rad51/Rad52-dependent manner in sgs 1 cells are more stable, as they can be efficiently visualized using standard protocols for 2D gel analysis (Supplementary Fig. S2). To gain insights into the nature of the rec-Xs and to address whether they may represent HJs, we treated the DNA preparations before 2D gel analysis with RuvC and T4 Endo VII resolvases that are known to cleave HJs (Lilley and White 2001). We found that even after extensive incubations with either RuvC or T4 Endo VII, the rec-Xs remain stable (Fig. 6A). We then tested whether the in vitro branch migration of the rec-X structures was prevented by the addition of $\mathrm{Mg}^{++}$. The four-way structure of HJs in the presence of $\mathrm{Mg}^{++}$folds pairwise in the coaxial stacking conformation that prevents branch migration (Panyutin and Hsieh 1994). We found that following incubation with $\mathrm{Mg}^{++}$, the $\mathrm{X}$ spike of the rec-X molecules is converted into a spot corresponding to linear molecules, thus implying

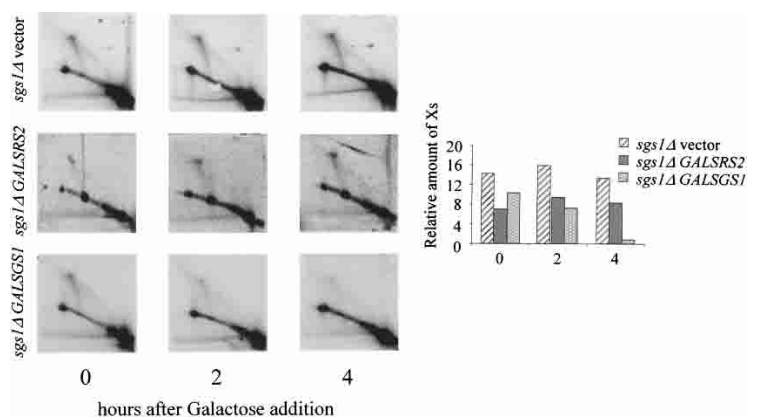

Figure 4. $S G S 1$, but not $S R S 2$, overexpression promotes the resolution of the $\mathrm{X}$-shaped intermediates accumulating in

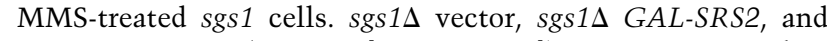
sgs1 $1 \Delta A L-S G S 1$ (CY2570 [pYES2-SGS1]) were grown in selective medium containing raffinose and treated with MMS for $3 \mathrm{~h}$. Galactose was then added to the medium to induce the overexpression of SRS2 or SGS1. Samples were taken at the indicated times and processed as in Figure 3. 
Liberi et al.

A

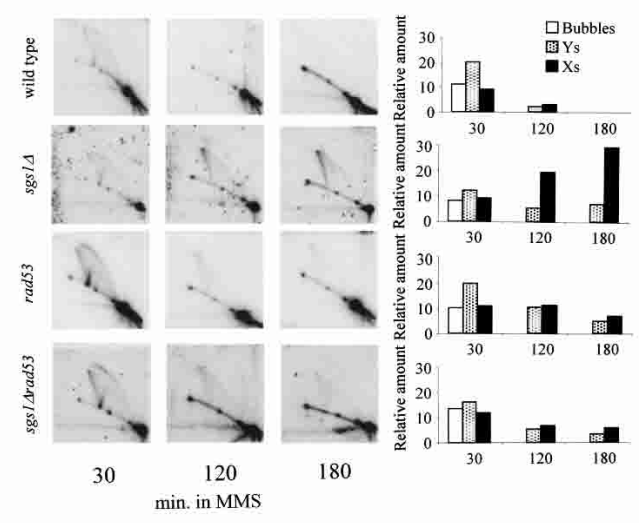

B

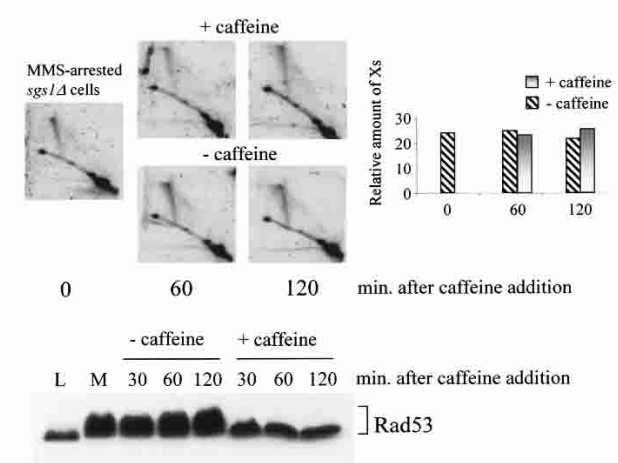

Figure 5. A functional Rad53 is required for formation of the $\mathrm{X}$-shaped intermediates accumulating in MMS-treated sgs1

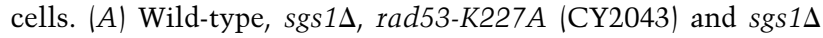
rad53-K227A (CY3319) strains were presynchronised in G1 by $\alpha$-factor treatment and released into fresh medium containing MMS. DNA samples were processed by 2D gel analysis as described in Figure 1B. $(B)$ sgs1s strain was presynchronised by $\alpha$-factor treatment in G1 and released into fresh medium containing MMS. After $3 \mathrm{~h}$ of MMS treatment (time 0), caffeine was added to half of the culture to inactivate the checkpoint cascade. At the indicated time points cell samples were taken and processed by $2 \mathrm{D}$ gel analysis as in Figure $1 \mathrm{~B}$ or by TCA protein extraction to assess the phosphorylation state of Rad53 kinase.

that the rec-Xs are able to branch migrate even in the presence of divalent cations (Fig. 6B). Altogether these results argue against the hypothesis that the rec-Xs represent canonical HJs. To test whether the rec-Xs contain ss-DNA, we treated them with ss-DNA nucleases such as Mung Bean and S1 nucleases. We found that the recXs, following incubation with Mung Bean or S1 nucleases are converted into smaller molecules that on $2 \mathrm{D}$ gel migrate with the typical mobility of double Ys (Fig. 6C; data not shown). We conclude that the rec-Xs indeed contain ss-DNA at discrete regions.

\section{Discussion}

We showed that in sgs1 cells, replication forks encountering a damaged template are engaged by homologous recombination pathways that promote the accumulation of X-shaped molecules. This event seems to be specifically amplified by MMS-induced DNA damage, as we failed to detect an accumulation of the same structures either under normal conditions or in response to HUinduced replication blockage. Hence, replication fork stalling per se is not sufficient to promote accumulation of rec-Xs. We note that MMS-induced intra-S DNA damage, although causing a delay in DNA synthesis, does not prevent fork progression. It is possible that the accumulation of the rec-Xs requires transient pausing induced by a damaged template coupled with ongoing DNA synthesis. This might also happen under normal conditions in response to endogenous DNA damage as also suggested by previous reports indicating that Sgs1 is required to prevent recombination in cells that have not been exposed to damaging agents (Gangloff et al. 2000; Klein 2001; McVey et al. 2001) although it would be impossible to detect such rare events by $2 \mathrm{D}$ analysis.

Once accumulated, these rec-Xs do not affect the progression of the fork. Hence, in sgs1 mutants, the forks do not collapse; rather they are able to proceed at the same rate as in wild-type cells and are capable of restarting DNA synthesis, even during recovery from an HU block (data not shown). Thus the sgs1 defect differs from the one seen in rad53 cells.

This is also consistent with the observation that, while MMS-treated rad53 cells exhibit unscheduled

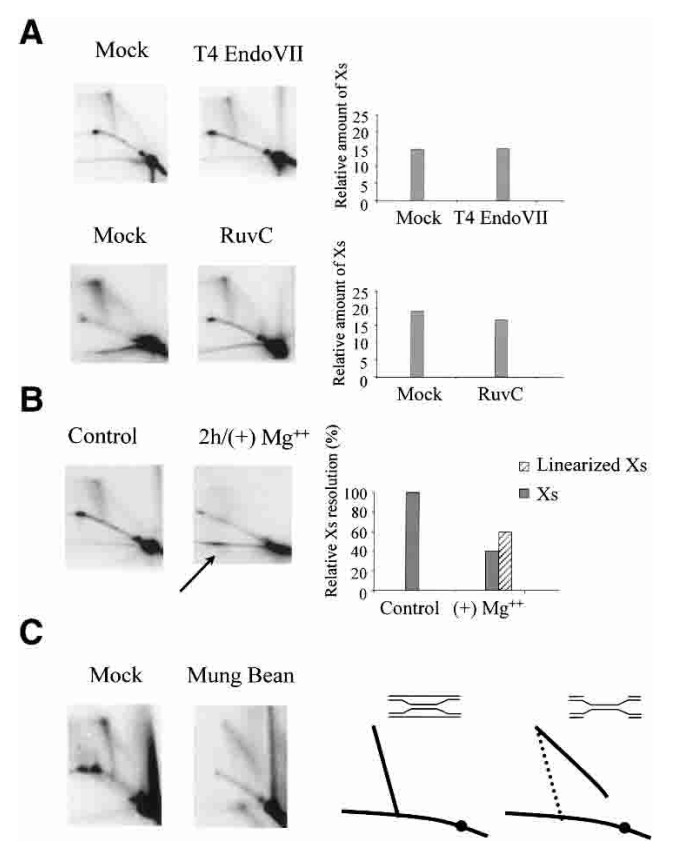

Figure 6. In vitro analysis of rec-X molecules. DNA samples, prepared from MMS-treated sgs1 cells as described in Figure 2B, were cut with NcoI and treated with RuvC and T4 Endo VII $(A)$ or subjected to a branch migration assay $(B)$. The arrow in $B$ indicates the linearized $\mathrm{X}$ molecules. $(C)$ The same structures were treated with Mung Bean nuclease. The scheme represents a possible structure of the rec-X exposed to Mung Bean nuclease treatment. 
firing of late/dormant origins (Shirahige et al. 1998), sgs1 mutants do not (data not shown). sgs1 cells have been implicated upstream in the checkpoint pathway based on the observations that, in response to MMS treatment, they seem to complete replication faster than wild-type cells at least by FACS profile and that $\operatorname{Rad} 53$ activation is partially dependent on a functional Sgs1 (Frei and Gasser 2000). Our data indicate that (1) sgs1 cells fire the origins prematurely, but fork progression and the bulk of DNA synthesis in the presence of MMS, at least under our experimental conditions, are not accelerated compared to wild-type cells; (2) sgs1 cells do not exhibit the unscheduled activation of late and dormant origins and the fork collapse typical of rad53 cells; rather, the accumulation of rec-X molecules in $s g s 1$ cells depends on a functional Rad53 kinase; (3) we found that MMS-treated sgs1 mutants accumulate more unphosphorylated Rad53 than wild-type cells (Supplementary Fig. S3). However, this apparent failure to properly activate Rad53 is fully restored in sgs 1 rad51 double mutants (Supplementary Fig. S3). A possible interpretation of this last result is that the engagement of replication forks into Rad51-dependent recombination structures in sgs1 mutants might indirectly mask the checkpoint signal, perhaps through the unscheduled formation of Rad51 filaments that would compete with the checkpoint signals represented by RPA-ss-DNA filaments (Zou and Elledge 2003; Lucca et al. 2004). This is also consistent with the observation that HU-treated sgs1 cells that do not exhibit Rad51-dependent structures at the forks activate the Rad53 kinase at the same extent as wild-type cells (Frei and Gasser 2000; data not shown).

Based on our observations we conclude that sgs1 cells are proficient in the signal transduction pathway leading to activation of the Rad53 kinase and that the apparent inability to fully elicit a checkpoint response is likely due to the unrestrained recombination events that actively limit the amount of checkpoint signal.

We also show that Sgs1, but not Srs2, promotes the resolution of the recombination-dependent structures that accumulate at damaged replication forks. This is also consistent with biochemical and genetic observations that implicate Srs2 specifically in inhibiting the initiation of recombination by dismantling Rad51 nucleofilaments (Chanet et al. 1996; Fabre et al. 2002; Ira et al. 2003; Krejci et al. 2003; Veaute et al. 2003), while RecQ helicases appear to be involved in the maturation of recombination intermediates (Harmon and Kowalczykowski 1998; Bennett et al. 1999; Gangloff et al. 1999; Constantinou et al. 2000; Karow et al. 2000; Fabre et al. 2002; Shor et al. 2002; Wu et al. 2002; Ira et al. 2003; Wu and Hickson 2003). Moreover, whereas MMS-treated srs2 cells do not exhibit accumulation of recombination structures at damaged forks (Fig. 7), Srs2 can counteract the formation of rec-Xs when it is overexpressed in sgs1 cells. We speculate that, in srs 2 mutants, a functional Sgs1 helicase is sufficient to deal with the resolution of rec-Xs at damaged forks. This hypothesis implies that Sgs1 plays the major role in preventing rec-Xs accumu-

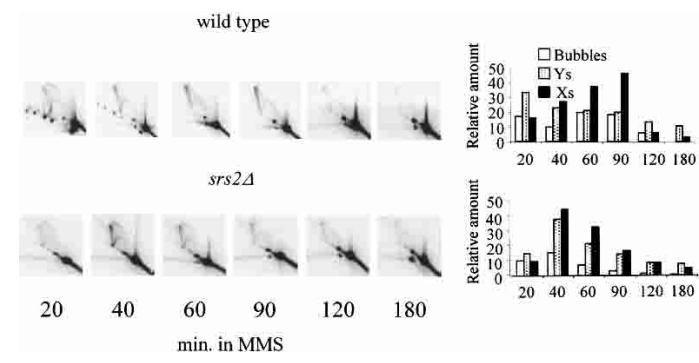

Figure 7. Analysis of replication intermediates in MMStreated srs2 cells. Wild-type and srs2 cells (CY2643) were processed by 2D gel analysis using the ARS305 probe as described in Figure 2.

lation in response to intra-S DNA damage while, in contrast, Srs2 is unable to fully counteract the formation of these structures unless it is overexpressed. In support of this conclusion, we showed that Srs2, differently from Sgs1, is unable to promote the resolution of the recombination structures that have already formed at the forks, implying that the two helicases counteract fork-induced recombination events through different mechanisms. This is also in accordance with genetic data suggesting that, during spontaneous DNA damage or in response to DSB, Sgs1 and Srs2 play indeed different roles in preventing recombination (Fabre et al. 2002; Ira et al. 2003), although overexpressing one of these helicases will suppress many phenotypes of the other (Mankouri et al. 2002; Ira et al. 2003). It is possible that the different roles played by the two helicases are influenced by the association with other cofactors. Topoisomerase 3, a Sgs1interacting protein, is a likely candidate, as we found that MMS-treated top3 and sgs1 top3 cells accumulate $\mathrm{X}$-shaped molecules like sgs1 mutants (Fig. 8). This observation suggests that both Sgs1 and Top3 are implicated in the maturation of the rec-X molecules. This is also in accordance with other reports indicating that RecQ helicases and Top3 functionally and physically interact (Gangloff et al. 1994; Harmon et al. 1999; Bennet et al. 2000; Fricke et al. 2001; Ira et al. 2003; Wu and Hickson 2003).

We failed to detect accumulation of rec-Xs in MMStreated wild-type cells (see also Lopes et al. 2003). The simplest explanation is that the coordinated action of Srs2 and Sgs1/Top3 efficiently counteracts the accumulation of such X-shaped molecules at damaged forks by preventing their formation and/or by promoting their turnover, thus precluding their visualization.

What is the molecular nature of the rec-Xs? More work will be required to firmly establish the physical nature of these structures. However we can formulate some hypotheses. In general, four-branched molecules migrate on 2D gels in the so-called X spike (Brewer and Fangman 1987). X-shaped structures on $2 \mathrm{D}$ gels have been related to HJs (Collins and Newlon 1994; Lockshon et al. 1995; Schwacha and Kleckner 1995; Zou and Rothstein 1997) or to hemicatenanes (Lucas and Hyrien 2000; Lopes et al. 2003; Wellinger et al. 2003). The X-shaped SCJ structure 


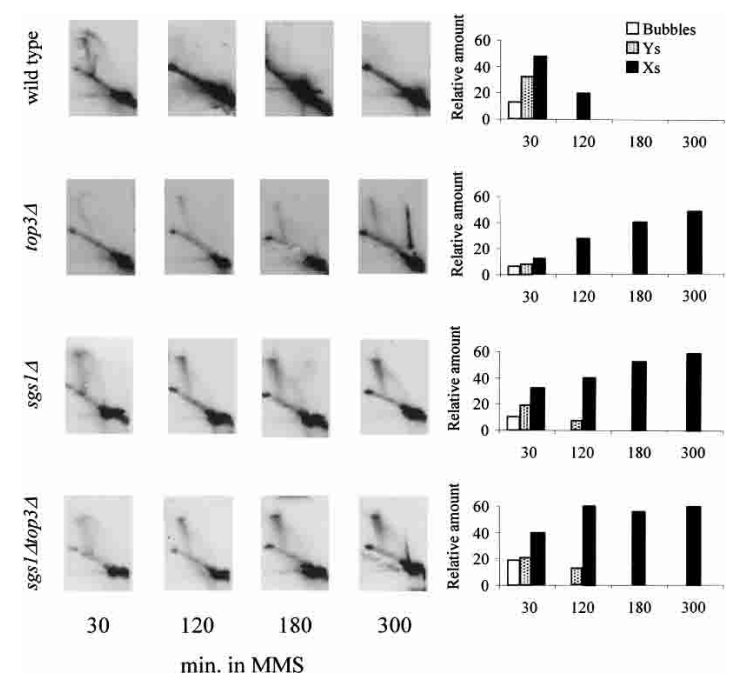

Figure 8. top3 mutants accumulate $\mathrm{X}$-shaped molecules at replication forks following exposure to MMS. Wild-type (CY5881), top3s (CY5893) sgs1s (CY5885), and sgs1s top3s (CY5889) strains were presynchronised in G1 by $\alpha$-factor treatment and released into fresh medium containing MMS. DNA samples were processed by $2 \mathrm{D}$ gel analysis using the ARS305 probe as in Figure 2.

that forms during origin firing, based on its properties, has been related to a hemicatenane molecule in which one strand of a duplex is coiled around one strand of the other duplex (Lopes et al. 2003). Hemicatenanes differ from HJs as there is no base pairing in the coiled region, and their formation does not require homologous recombination. We note that, differently from HJs, SCJs/hemicatenanes are able to branch migrate even in the presence of divalent cations and are resistant to RuvC treatment (Lopes et al. 2003; data not shown). The last two properties are also shared by rec-Xs; however, we show that the rec-Xs can be distinguished from SCJs based on the genetic requirement and the relative stability during purification of replication intermediates. The data presented in Figure 6 argue against the hypothesis that the rec-Xs represent canonical HJs. Moreover, the finding that the absence of a functional checkpoint precludes the accumulation of the rec-Xs in sgs1 cells experiencing intra-S DNA damage is consistent with the hypothesis that the SCJs represent a potential source of the rec-Xs. Rad53 stabilizes stalled forks (Lopes et al. 2001), replisome-fork association (Lucca et al. 2004) and SCJs (Lopes et al. 2003). In rad53 cells, the SCJs form normally at origins of replication, can still chase replication forks, but rapidly degenerate when they run off at replisomedeprived forks. Hence, it is possible that in rad53 sgs1 cells the unscheduled resolution of the SCJs at damaged forks is the cause of the lack of accumulation of the rec-Xs. Accordingly, the checkpoint seems to specifically affect the formation of the rec-Xs rather than their resolution. It should be pointed out that hemicatenanes can be converted into double HJs (Schwacha and Kleckner 1995) or in pseudo double HJs (Lopes et al. 2003) if the pairing is restricted to the newly synthesized strands.
Based on the following considerations, we suspect that the rec-Xs represent pseudo double HJs: (1) They are expected to be more stable than SCJs due to the extensive pairing between the nascent chains /conversely, a simple nick on the coiled region of the hemicatenane would resolve its structure); (2) it is expected that these structures contain ss-DNA regions and that, following treatments with ss-DNA nucleases, they would be converted into molecules mimicking the structures of double Ys (Fig. 6C); (3) they would differ from canonical HJs, thus explaining the inability to be cleaved by RuvC and $\mathrm{T} 4$ Endo VII resolvases and to migrate in the presence of divalent cations. In this, they would rather resemble hemicatenanes. Although other possibilities could be envisaged, altogether our observations could be explained by the model presented in Figure 9. Forks hitting a damaged template could undergo a transient uncoupling between leading and lagging strand synthesis (Pages and Fuchs 2003). This pausing could provide enough time for the SCJ/hemicatenane to reach the stalled strand, thus promoting pairing between the two newly synthesized strands and, consequently, template switching (transition from A to B in Fig. 9; Lopes et al. 2003). Rad53, by

A

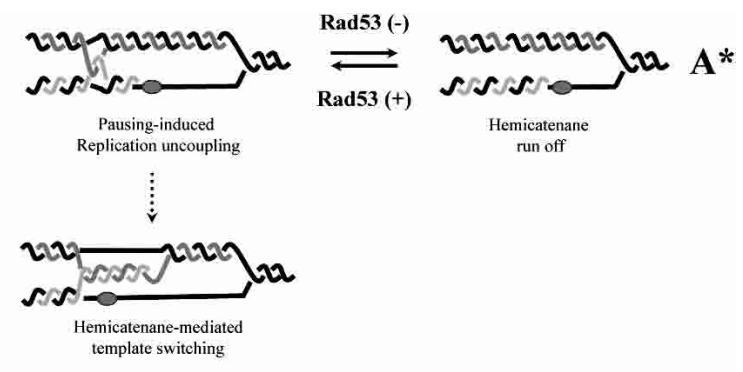

$\operatorname{Rad51/52} \downarrow \uparrow$ Srs2

C
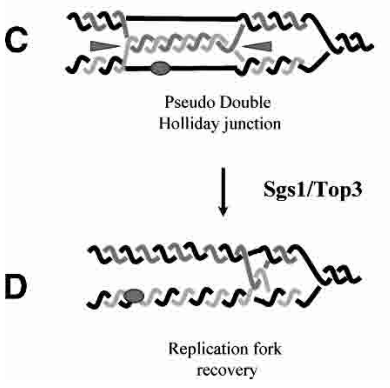

Figure 9. A model for DNA damage replication bypass mediated by Sgs1 helicases. Replication forks encountering a damaged template bypass DNA lesions (indicated by the oval shape) through template switching mediated by hemicatenanes (transition from $A$ to $B$ ) (see text for further details). Rad53 contributes to maintaining the integrity of the SCJ/hemicatenanes by preventing their runoff (transition $A$ to $\left.A^{*}\right)$. A Rad51/Rad52 homologous-dependent pathway converts/stabilizes the $B$ intermediates into pseudo double $\mathrm{HJ}$ by extending pairing between newly synthesized strands (transition from $B$ to $C$ ). This transition might be counteracted by Srs 2 translocase activity. The Sgs1/Top3 complex (indicated by triangles) reconverts the pseudo double HJs back into SCJs (transition from $C$ to $D)$. 
stabilizing replisome-fork complexes (Lucca et al. 2004), would prevent the Exol-mediated conversion of SCJs into gapped molecules (Cotta-Ramusino et al. 2005) that represent the vast majority of abnormal replication intermediates accumulating in rad53 cells (transition from A to $\mathrm{A}^{\star}$ in Fig. 9; Sogo et al. 2002). Template switching would then allow DNA synthesis to overcome the lesion on the template (Higgins et al. 1976). Occasionally the template-switched structure could be engaged by Rad51 and Rad52, thus forming more stable structures $(\operatorname{Rad} 51$ nucleofilaments) characterized by extensive pairing (transition from B to C in Fig. 9). We cannot exclude the possibility that Rad51 and Rad52 contribute also to form and/or stabilize the template-switched structure. Srs2 could be implicated in preventing this transition or in limiting the region engaged in base pairing by destabilizing Rad51 nucleofilaments (Krejci et al. 2003; Veaute et al. 2003). The reestablishment or the normal replication fork could be mediated by Sgs1 and Top3 by collapsing the pseudo double $\mathrm{HJ}$ back into the SCJ conformation (transition from C to D in Fig. 9). Hence, in this view, the pseudo double HJs represented in Figure 9C are in fact more complex hemicatenanes and the extension of the hemicatenated region would depend on the extension of the region synthesized during template switching. However, we cannot exclude the possibility that a fraction of these pseudo double HJs are enzymatically converted into proper double HJs by extending the pairing to the parental strands. Further, considering that Sgs1 and Top3 have been implicated in replication termination (Wang 1991; Rothstein and Gangloff 1995) in should be noted that the pseudo double HJs are expected to represent a typical Top3 substrate as they resemble the termination intermediates arising when replication forks converge.

The mechanism proposed in Figure 9 would allow error-free replication across template lesions and the preservation of the hemicatenane structure. Based on this model, sgs1 mutants would accumulate pseudo double HJs though the action of Rad51 and Rad52. Further, while Srs2 would have a role in counteracting the formation of the pseudo HJs, Sgs1 and Top3 would instead be implicated in their maturation into SCJs. In rad53 sgs 1 double mutants, a consistent fraction of SCJs would rapidly degenerate, thus limiting those intermediates that mediate template switching; this, in turn, would prevent the accumulation of the pseudo double HJs.

This model also implies that mutations in factors involved in the formation of SCJs might exhibit recombination defects, although such factors have not been identified yet.

Altogether our data provide the first physical evidence that, in RecQ helicase mutants, recombination intermediates accumulate during chromosome replication when forks hit a damaged template. We speculate that the pathological resolution of these structures may contribute to genome instability and hyperecombination that are hallmarks of BLM cells (German 1993; Hickson 2003).

\section{Materials and methods}

Strains and plasmids

All the strains used in this study are isogenic derivatives of W303-1A (Thomas and Rothstein 1989). SGS1, SRS2, TOP3, $R A D 51$, and $R A D 52$ deletion strains were constructed using the PCR-based gene disruption strategy already described by Wach et al. (1994).

Plasmids pAN8 [GAL-SRS2] and pAN11 [GAL-srs2-K41A] were obtained by placing the SRS2 ORF or srs2-K41A mutated sequence, respectively, under the control of the GAL1 inducible promoter in pYES2 multicopy vector. Plasmid pYES2-SGS1 is described by Mankouri et al. (2002).

Growing conditions, cell cycle arrests, and drug treatments

Unless otherwise indicated, strains were grown at $28^{\circ} \mathrm{C}$ in YPD medium containing glucose at $2 \% \mathrm{w} / \mathrm{v}$. Galactose and raffinose were also used at $2 \% \mathrm{w} / \mathrm{v}$.

Cell synchronization was performed by adding $2 \mu \mathrm{g} / \mathrm{mL} \alpha$-factor to the cultures and by evaluating the percentage of unbudded cells. The release from $\alpha$-factor arrest was performed by centrifugation and resuspension of cells in fresh medium. MMS, $\mathrm{HU}$, and caffeine were used at final concentrations of $0.033 \%$ $\mathrm{v} / \mathrm{v}, 0.2 \mathrm{M}$, and $10 \mathrm{mg} / \mathrm{mL}$, respectively.

DNA extraction, 2D gel technique, FACS, and protein analysis

Purification of DNA intermediates in the presence of CTAB, 2D gel procedure, and quantification analysis of autoradiograms were carried out as already described by Lopes et al. (2001, 2003). FACS analysis was performed using a Beckton Dickinson fluorescence-activated cell analyzer, as described by Liberi et al. (2000). TCA protein extraction, SDS-PAGE, and Western blot procedures have also been already described (Liberi et al. 2000). Rad53, Srs2, and Sgs1 were analyzed using polyclonal antibodies JD47 (kindly provided by J. Diffley, Cancer Research UK, South Mimms, UK), YC-18, and YC-17 (Santa Cruz Biotechnology), respectively.

\section{In vitro analysis of $X$-shaped molecules}

Following first-dimension gel electrophoresis, the slices of agarose were incubated in branch migration buffer $(10 \mathrm{mM}$ Tris$\mathrm{HCl}$ at $\mathrm{pH} 8.0,50 \mathrm{mM} \mathrm{NaCl}, 10 \mathrm{mM} \mathrm{MgCl} 2,0.1 \mathrm{mM}$ EDTA), as described by Panyutin and Hsieh (1994). Agarose lanes were then subjected to second-dimension gel electrophoresis.

DNA samples, prepared from MMS-treated wild-type and sgs 1 cells, were incubated at $37^{\circ} \mathrm{C}$ before $2 \mathrm{D}$ gel electrophoresis with cleavage enzymes at the following conditions: RuvC (kindly provided by I. Hickson, Cancer Research UK, Oxford, $\mathrm{UK})$ at $100 \mu \mathrm{g}$ for $20 \mathrm{~h}$ in buffer containing $12 \mathrm{mM}$ Tris- $\mathrm{HCl}(\mathrm{pH}$ 8.0), $10 \mathrm{mM} \mathrm{MgCl}, 1 \mathrm{mM} \mathrm{DTT}, 100 \mu \mathrm{g} / \mathrm{mL} \mathrm{BSA}$; T4 Endo VII (USB Corporation), Mung Bean, and S1 (Amersham) were used at $1000 \mathrm{U}$ for $20 \mathrm{~h}, 50 \mathrm{U}$ for $1 \mathrm{~h}$, and $40 \mathrm{U}$ for $1 \mathrm{~h}$, respectively, in the manufacturer's recommended reaction buffers.

\section{Acknowledgments}

We thank J. Diffley, F. Fabre, L. Fabiani, I. Hickson, G. Ira, H. Mankouri, C. Newlon, J. Sogo, R. Rothstein, R. Wellinger, L. Wu, M. Whitby, V. Zakian, and all members of our laboratories for reagents, procedures, and helpful discussions. We are particularly grateful to H. Mankouri and I. Hickson for sharing unpublished observations with us. We also thank the Sequenc- 
ing Facility at IFOM. This work was supported by Associazione Italiana per la Ricerca sul Cancro, European Union, and partially by Telethon grant GGP030412 and Ministero della Salute. J.E.H. is supported by NIH grant GM61766 and I.C. and C.L. are supported by fellowships from Fondazione Italiana per la Ricerca sul Cancro and Fondazione Adriano Buzzati-Traverso, respectively.

\section{References}

Aboussekhra, A., Chanet, R., Zgaga, Z., Cassier-Chauvat, C., Heude, M., and Fabre, F. 1989. RADH, a gene of Saccharomyces cerevisiae encoding a putative DNA helicase involved in DNA repair. Characteristics of $\mathrm{radH}$ mutants and sequence of the gene. Nucleic Acids Res. 17: 7211-7219.

Aylon, Y., Liefshitz, B., Bitan-Banin, G., and Kupiec, M. 2003. Molecular dissection of mitotic recombination in the yeast Saccharomyces cerevisiae. Mol. Cell. Biol. 23: 1403-1417.

Bennett, R.J., Keck, J.L., and Wang, J.C. 1999. Binding specificity determines polarity of DNA unwinding by the Sgs1 protein of S. cerevisiae. J. Mol Biol. 289: 235-248.

Bennet, R.J., Noirot-Gros, M.F., and Wang, J.C. 2000. Interaction between yeast Sgs1 helicase and DNA topoisomerase III. J. Biol. Chem. 275: 26898-26905.

Brewer, B.J. and Fangman, W.L. 1987. The localization of replication origins on ARS plasmids in S. cerevisiae. Cell 51: 463-471.

Carr, A.M. 2002. DNA structure dependent checkpoints as regulators of DNA repair. DNA Repair 1: 983-994.

Chanet, R., Heude, M., Adjiri, A., Maloisel, L., and Fabre, F. 1996. Semidominant mutations in the yeast Rad51 protein and their relationships with the Srs2 helicase. Mol. Cell. Biol. 16: 4782-4789.

Collins, I. and Newlon, C.S. 1994. Meiosis-specific formation of joint DNA molecules containing sequences from homologous chromosomes. Cell 76: 65-75.

Constantinou, A., Tarsounas, M., Karow, J.K., Brosh, R.M., Bohr, V.A., Hickson, I.D., and West, S.C. 2000. Werner's syndrome protein (WRN) migrates Holliday junctions and colocalizes with RPA upon replication arrest. EMBO Rep. 1: 80-84.

Cotta-Ramusino, C., Fachinetti, D., Lucca, C., Doksani, Y., Lopes, M., Sogo, J., and Foiani, M. 2005. Exol nuclease processes stalled replication forks and counteracts fork reversal in the absence of a functional S-phase checkpoint. Mol. Cell 17: $1-20$.

Cox, M.M. 2001. Historical overview: Searching for replication help in all the rec places. Proc. Natl. Acad. Sci. 98: 81738180 .

Davis, A.P. and Symington, L.S. 2004. RAD51-dependent breakinduced replication in yeast. Mol. Cell. Biol. 24: 2344-2351.

Fabre, F., Chan, A., Heyer, W.D., and Gangloff, S. 2002. Alternate pathways involving Sgs1/Top3, Mus81/Mms4, and Srs2 prevent formation of toxic recombination intermediates from single-stranded gaps created by DNA replication. Proc. Natl. Acad. Sci. 99: 16887-16892.

Flores-Rozas, H. and Kolodner, R.D. 2000. Links between replication, recombination and genome instability in eukaryotes. Trends Biochem. Sci. 25: 196-200.

Foiani, M., Pellicioli, A., Lopes, M., Lucca, C., Ferrari, M., Liberi, G., Muzi-Falconi, M., and Plevani, P. 2000. DNA damage checkpoints and DNA replication controls in Saccharomyces cerevisiae. Mutat. Res. 451: 187-196.

Frei, C. and Gasser, S.M. 2000. The yeast Sgs1p helicase acts upstream of Rad53p in the DNA replication checkpoint and colocalizes with Rad53p in S-phase-specific foci. Genes \& Dev. 14: 81-96.

Fricke, W.M., Kaliraman, V., and Brill, S.J. 2001. Mapping the DNA topoisomerase III binding domain of the Sgs1 DNA helicase. J. Biol. Chem. 276: 8848-8855.

Gangloff, S., McDonald, J.P., Bendixen, C., Arthur, L., and Rothstein, R. 1994. The yeast type I topoisomerase Top3 interacts with Sgs1, a DNA helicase homolog: A potential eukaryotic reverse gyrase. Mol. Cell. Biol. 14: 8391-8398.

Gangloff, S., de Massy, B., Arthur, L., Rothstein, R., and Fabre, F. 1999. The essential role of yeast topoisomerase III in meiosis depends on recombination. EMBO J. 18: 1701-1711.

Gangloff, S., Soustelle, C., and Fabre, F. 2000. Homologous recombination is responsible for cell death in the absence of the Sgs1 and Srs2 helicases. Nature Genet. 25: 192194.

German, J. 1993. Bloom syndrome: A Mendelian prototype of somatic mutational disease. Medicine 72: 393-406.

Harmon, F.G. and Kowalczykowski, S.C. 1998. RecQ helicase, in concert with RecA and SSB proteins, initiates and disrupts DNA recombination. Genes \& Dev. 12: 1134-1144.

Harmon, F.G., DiGate, R.J., and Kowalczykowski, S.C. 1999. RecQ helicase and topoisomerase III comprise a novel DNA strand passage function: A conserved mechanism for control of DNA recombination. Mol. Cell 3: 611-620.

Hegde, V. and Klein, H.L. 2000. Requirement for the SRS2 DNA helicase gene in non-homologous end joining in yeast. Nucleic Acids Res. 28: 2779-2783.

Heyer, W.D., Ehmsen, K.T., and Solinger, J.A. 2003. Holliday junctions in the eukaryotic nucleus: Resolution in sight? Trends Biochem. Sci. 28: 548-557.

Hickson, I. D. 2003. RecQ helicases: Caretakers of the genome. Nat. Rev. Cancer 3: 169-178.

Higgins, N.P., Kato, K., and Strauss, B. 1976. A model for replication repair in mammalian cells. J. Mol. Biol. 101: 417425.

Huang, P.H., Pryde, F.E., Lester, D., Maddison, R.L., Borts, R.H., Hickson, I.D., and Louis, E.J. 2001. SGS1 is required for telomere elongation in the absence of telomerase. Curr. Biol. 11: 125-129.

Inman, R.B. 1984. Methodology for the study of effect of drugs on development and DNA replication in Drosophyla melanogaster embryonic tissue. Biochim. Biophys. Acta. 783: 205-215.

Ira, G. and Haber, J.E. 2002. Characterization of RAD51-independent break-induced replication that acts preferentially with short homologous sequences. Mol. Cell. Biol. 22: 63846392.

Ira, G., Malkova, A., Liberi, G., Foiani, M., and Haber, J.E. 2003. Srs2 and Sgs1-Top3 suppress crossovers during doublestrand break repair in yeast. Cell 115: 401-411.

Karow, J.K., Constantinou, A., Li, J.L., West, S.C., and Hickson, I.D. 2000. The Bloom's syndrome gene product promotes branch migration of Holliday junctions. Proc. Natl. Acad. Sci. 97: 6504-6508.

Khakhar, R.R., Cobb, J.A., Bjergbaek, L., Hickson, I.D., and Gasser, S.M. 2003. RecQ helicases: Multiple roles in genome maintenance. Trends Cell Biol. 13: 493-501.

Klein, H.L. 2001. Mutations in recombinational repair and in checkpoint control genes suppress the lethal combination of srs $2 \Delta$ with other DNA repair genes in Saccharomyces cerevisiae. Genetics 157: 557-565.

Kogoma, T. 1997. Stable DNA replication: Interplay between DNA replication, homologous recombination, and transcription. Microbiol. Mol. Biol. Rev. 61: 212-238.

Kowalczykowski, S.C. 2000. Initiation of genetic recombina- 
tion and recombination-dependent replication. Trends Biochem. Sci. 25: 156-165.

Krejci, L., Van Komen, S., Li, Y., Villemain, J., Reddy, M.S., Klein, H., Ellenberger, T., and Sung, P. 2003. DNA helicase Srs2 disrupts the Rad51 presynaptic filament. Nature 423: 305-309.

Krejci, L., Macris, M., Li, Y., Komen, S.V., Villemain, J., Ellenberger, T., Klein, H., and Sung, P. 2004. Role of ATP hydrolysis in the anti-recombinase function of Saccharomyces cerevisiae Srs2 protein. J. Biol. Chem. 279: 23193-23199.

Liberi, G., Chiolo, I., Pellicioli, A., Lopes, M., Plevani, P., MuziFalconi, M., and Foiani, M. 2000. Srs2 DNA helicase is involved in checkpoint response and its regulation requires a functional Mec1-dependent pathway and Cdk1 activity. EMBO J. 19: 5027-5038.

Lilley, D.M.J. and White, M.F. 2001. The junction-resolving enzymes. Nat. Rev. Mol. Cell. Biol. 2: 433-443.

Lockshon, D., Zweifel, S.G., Freeman-Cook, L.L., Lorimer, H.E., Brewer, B.J., and Fangman, W.L. 1995. A role for recombination junctions in the segregation of mitochondrial DNA in yeast. Cell 81: 947-955.

Lopes, M., Cotta-Ramusino, C., Pellicioli, A., Liberi, G., Plevani, P., Muzi-Falconi, M., Newlon, C.S., and Foiani, M. 2001. The DNA replication checkpoint response stabilizes stalled replication forks. Nature 412: 557-561.

Lopes, M., Cotta-Ramusino, C., Liberi, G., and Foiani, M. 2003. Branch migrating sister chromatid junctions form at replication origins through Rad51/Rad52-independent mechanisms. Mol. Cell 12: 1499-1510.

Lucas, I. and Hyrien, O. 2000. Hemicatenanes form upon inhibition of DNA replication. Nucleic Acids Res. 28: 21872193.

Lucca, C., Vanoli, F., Cotta-Ramusino, C., Pellicioli, A., Liberi, G., Haber, J., and Foiani, M. 2004. Checkpoint-mediated control of replisome-fork association and signaling in response to replication pausing. Oncogene 23: 1206-1213.

Mankouri, H.W., Craig, T.J., and Morgan, A. 2002. SGS1 is a multicopy suppressor of srs2: Functional overlap between DNA helicases. Nucleic Acids Res. 30: 1103-1113.

McVey, M., Kaeberlein, M., Tissenbaum, H.A., and Guarente, L. 2001. The short life span of Saccharomyces cerevisiae sgs1 and srs 2 mutants is a composite of normal aging processes and mitotic arrest due to defective recombination. Genetics 157: 1531-1542.

Michel, B., Flores, M.J., Viguera, E., Grompone, G., Seigneur, M., and Bidnenko, V. 2001. Rescue of arrested replication forks by homologous recombination. Proc. Natl. Acad. Sci. 98: 8181-8188.

Murray, A.W. and Hunt, T. 1993. The cell cycle. W.H. Freeman, New York.

Myung, K. and Kolodner, R.D. 2002. Suppression of genome instability by redundant S-phase checkpoint pathways in Saccharomyces cerevisiae. Proc. Natl. Acad. Sci. 99: 45004507.

Myung, K., Datta, A., Chen, C., and Kolodner, R.D. 2001. SGS1, the Saccharomyces cerevisiae homologue of BLM and WRN, suppresses genome instability and homeologous recombination. Nature Genet. 27: 113-116.

Newlon, C.S., Collins, I., Dershowitz, A., Deshpande, A.M., Greenfeder, S.A., Ong, L.Y., and Theis, J.F. 1993. Analysis of replication origin function on chromosome III of Saccharomyces cerevisiae. Cold Spring Harbor Symp. Quant. Biol. 58: 415-423.

Onoda, F., Seki, M., Miyajima, A., and Enomoto, T. 2001. Involvement of SGS1 in DNA damage-induced heteroallelic recombination that requires $R A D 52$ in Saccharomyces cer- evisiae. Mol. Gen. Genet. 264: 702-708.

Ooi, S.L., Shoemaker, D.D., and Boeke, J.D. 2003. DNA helicase gene interaction network defined using synthetic lethality analyzed by microarray. Nat. Genet. 35: 277-286.

Pages, V. and Fuchs, R.P. 2003. Uncoupling of leading- and lagging-strand DNA replication during lesion bypass in vivo. Science 300: 1300-1303.

Panyutin, I.G. and Hsieh, P. 1994. The kinetics of spontaneuos DNA branch migration. Proc. Natl. Acad. Sci. 91: 20212025.

Pâques, F. and Haber, J.E. 1997. Two pathways for removal of nonhomologous DNA ends during double-strand break repair in Saccharomyces cerevisiae. Mol. Cell. Biol. 17: 67656771.

- 1999. Multiple pathways of recombination induced by double-strand breaks in Saccharomyces cerevisiae. Microbiol. Mol. Biol. Rev. 63: 349-404.

Paulovich, A.G. and Hartwell, L.H. 1995. A checkpoint regulates the rate of progression through $S$ phase in $S$. cerevisiae in response to DNA damage. Cell 82: 841-847.

Prince, P.R., Emond M.J., and Monnat Jr., R.J. 2001. Loss of Werner syndrome protein function promotes aberrant mitotic recombination. Genes \& Dev. 15: 933-938.

Rhind, N. and Russell, P. 2000. Checkpoints: It takes more than time to heal some wounds. Curr. Biol. 10: 908-911.

Rockmill, B., Fung, J.C., Branda, S.S., and Roeder, G.S. 2003. The Sgs1 helicase regulates chromosome synapsis and meiotic crossing over. Curr. Biol. 13: 1954-1962.

Rong, L. and Klein, H.L. 1993. Purification and characterization of the SRS2 DNA helicase of the yeast Saccharomyces cerevisiae. J. Biol. Chem. 268: 1252-1259.

Rong, L., Palladino, F., Aguilera, A., and Klein, H.L. 1991. The hyper-gene conversion hpr5-1 mutation of Saccharomyces cerevisiae is an allele of the $S R S 2 / R A D H$ gene. Genetics 127: 75-85.

Rothstein, R. and Gangloff, S. 1995. Hyper-recombination and Bloom's syndrome: Microbes again provide clues about cancer. Genome Res. 5: 421-426.

Schwacha, A. and Kleckner, N. 1995. Identification of double Holliday junctions as intermediates in meiotic recombination. Cell 83: 783-791.

Shen, J. and Loeb, L.A. 2001. Unwinding the molecular basis of the Werner syndrome. Mech. Ageing Dev. 122: 921-944.

Shirahige, K., Hori, Y., Shiraishi, K., Yamashita, M., Takahashi, K., Obuse, C., Tsurimoto, T., and Yoshikawa, H. 1998. Regulation of DNA-replication origins during cell-cycle progression. Nature 395: 618-621.

Shor, E., Gangloff, S., Wagner, M., Weinstein, J., Price, G., and Rothstein, R. 2002. Mutations in homologous recombination genes rescue top3 slow growth in Saccharomyces cerevisiae. Genetics 162: 647-662.

Signon, L., Malkova, A., Naylor, M.L., Klein, H., and Haber, J.E. 2001. Genetic requirements for RAD51- and RAD54-independent break-induced replication repair of a chromosomal double-strand break. Mol. Cell. Biol. 21: 2048-2056.

Sinclair, D.A., Mills, K., and Guarente, L. 1998. Molecular mechanisms of yeast aging. Trends Biochem. Sci. 23: 131134.

Sogo, J.M., Lopes, M., and Foiani, M. 2002. Fork reversal and ssDNA accumulation at stalled replication forks owing to checkpoint defects. Science 297: 599-602.

Tercero, J.S. and Diffley, J.F.X. 2001. Regulation of DNA replication fork progression through damaged DNA by the Mec1/ Rad53 checkpoint. Nature 412: 553-557.

Thomas, B.J. and Rothstein, R. 1989. Elevated recombination rates in transcriptionally active DNA. Cell 56: 619-630. 
Liberi et al.

Vaze, M., Pellicioli, A., Lee, S., Ira, G., Liberi, G., Arbel-Eden, A., Foiani, M., and Haber, J. 2002. Recovery from checkpoint-mediated arrest after repair of a double-strand break requires Srs2 helicase. Mol. Cell 10: 373-385.

Veaute, X., Jeusset, J., Soustelle, C., Kowalczykowski, S.C., Le Cam, E., and Fabre, F. 2003. The Srs2 helicase prevents recombination by disrupting Rad51 nucleoprotein filaments. Nature 423: 309-312.

Wach, A., Brachat, A., Pohlmann, R., and Philippsen, P. 1994. New heterologous modules for classical or PCR-based gene disruptions in Saccharomyces cerevisiae. Yeast 10: 17931808.

Wang, J.C. 1991. DNA topoisomerases: Why so many? J. Biol. Chem. 266: 6659-6662.

Watt, P.M., Hickson, I.D., Borts, R.H., and Louis, E.J. 1996. SGS1, a homologue of the Bloom's and Werner' syndrome genes, is required for maintenance of genome stability in Saccharomyces cerevisiae. Genetics 144: 935-945.

Wellinger, R.E., Schar, P., and Sogo, J.M. 2003. Rad52-independent accumulation of joint circular minichromosomes during S phase in Saccharomyces cerevisiae. Mol. Cell. Biol. 23: 6363-6372.

West, S.C. 2003. Molecular views of recombination proteins and their control. Nat. Rev. Mol. Cell Biol. 4: 435-445.

Wu, L. and Hickson, I.D. 2003. The Bloom's syndrome helicase suppresses crossing over during homologous recombination. Nature 426: 870-874.

Wu, L., Davies, S.L., Levitt, N.C., and Hickson, I.D. 2002. Potential role for the BLM helicase in recombinational repair via a conserved interaction with RAD51. J. Biol. Chem. 276: 19375-19381.

Zou, L. and Elledge, S.J. 2003. Sensing DNA damage through ATRIP recognition of RPA-ssDNA complexes. Science 300: 1542-1548.

Zou, H. and Rothstein, R. 1997. Holliday junctions accumulate in replication mutants via a RecA homolog-independent mechanism. Cell 90: 87-96. 


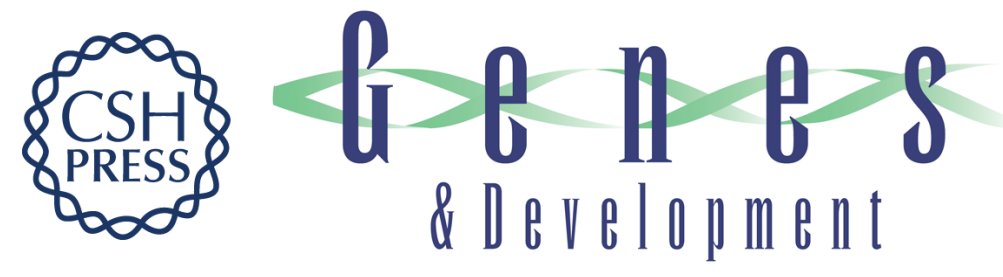

\section{Rad51-dependent DNA structures accumulate at damaged replication forks in sgs1 mutants defective in the yeast ortholog of BLM RecQ helicase}

Giordano Liberi, Giulio Maffioletti, Chiara Lucca, et al.

Genes Dev. 2005, 19:

Access the most recent version at doi:10.1101/gad.322605

Supplemental http://genesdev.cshlp.org/content/suppl/2005/01/13/19.3.339.DC1

Material

References This article cites 82 articles, 37 of which can be accessed free at: http://genesdev.cshlp.org/content/19/3/339.full.html\#ref-list-1

License

Email Alerting Receive free email alerts when new articles cite this article - sign up in the box at the top Service right corner of the article or click here.

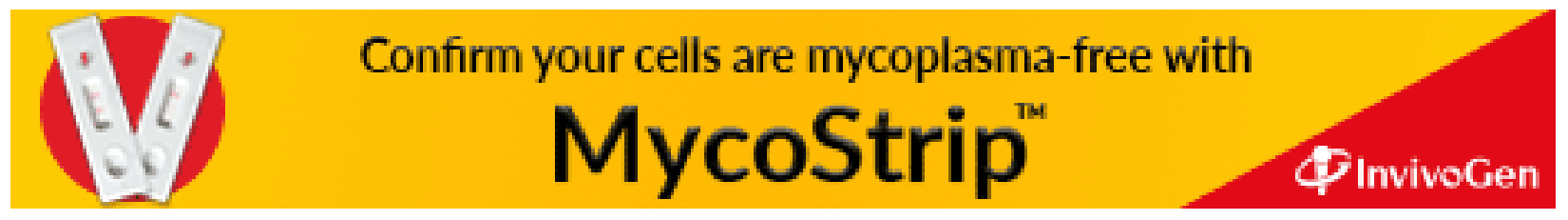

